Pablo Cardinal-Fernández ${ }^{1,}$ Esteban Garcia Cuesta ${ }^{2 *}$

José Barberán $3^{3^{*}}$

José F. Varona ${ }^{3}$

Alberto Estirado ${ }^{4}$

Alberto Moreno ${ }^{5}$

Julio Villanueva ${ }^{6}$

Mercedes Villareal ${ }^{7}$

Orville Baez-Pravia ${ }^{1}$

Justo Menéndez ${ }^{8}$

Paula Villares ${ }^{9}$

Alejandro López Escobar ${ }^{10}$

Jesús Rodríguez-Pascual| ${ }^{11}$

Cristina Almirall ${ }^{12}$

Eduardo Dominguez

Carlos Pey ${ }^{1}$

Antonio Ferreiro ${ }^{13}$

Manuel Revilla Amores ${ }^{14}$

Nike Sánchez ${ }^{15}$

Santiago Ruiz de Aguiar ${ }^{16}$

José M. Castellano ${ }^{17}$

\section{Clinical characteristics and outcomes of 1,331 patients with COVID-19: HM Spanish Cohort}

${ }^{1}$ Intensive Care Unit, HM Hospitals Group. Madrid, Spain

${ }^{2}$ Science, Computing, and Technology Department, School of Architecture, Engineering and Design, Univ. Europea de Madrid, Villaviciosa de Odón, Madrid, Spain

${ }^{3}$ Internal Medicine Department, Hospital Universitario HM Monteprincipe, Madrid, Spain

Medicine School, CEU San Pablo University

${ }^{4}$ Chief of Information Officer, HM Hospitals Group. Madrid, Spain

${ }^{5}$ Chief of Software, Development and Data Analytics Department - HM Hospitals Group, Madrid. Spain

${ }^{6}$ Medical Director, Hospital Universitario HM Sanchinarro, Madrid, Spain

${ }^{7}$ Internal Medicine Department, Hospital Universitario HM Torrelodones, Madrid, Spain

${ }^{8}$ Emergency Department, HM Hospitales Groups, Madrid, Spain

${ }^{9}$ Internal Medicine Department, Hospital Universitario HM Sanchinarro, Madrid, Spain

${ }^{10}$ Pediatric Unit, HM Puerta del Sur, Madrid, Spain

${ }^{11}$ Oncology Unit, HM Hospitales, Madrid, Spain

${ }^{12}$ ABACID Laboratory - HM Hospitales, Madrid, Spain

${ }^{13}$ Radiology Department, Hospital Universitario HM Madrid. Madrid, Spain

${ }^{14}$ Internal Medicine Department, Hospital HM Valles. Alcala de Henares, Madrid, Spain

${ }^{15}$ Medical Director, Hospital Universitario HM Puerta del Sur, Madrid, Spain

${ }^{16}$ Territorial Director of HM Hospitales Groups, Madrid, Spain

${ }^{17}$ Scientific director - HM Hospitales research foundation, Madrid, Spain

Article history

Received: 21 March 2021; Accepted: 9 April 2021; Published: 19 May 2021

\section{ABSTRACT}

Background. Spain is one of the European countries most affected by the COVID-19 pandemic. Epidemiologic studies are warranted to improve the disease understanding, evaluate the care procedure and prepare for futures waves. The aim of the study was to describe epidemiologic characteristics associated with hospitalized patients with COVID-19.

Methods. This real-world, observational, multicenter and retrospective study screened all consecutive patients admitted to 8 Spanish private hospitals. Inclusion criteria: hospitalized adults (age $\geq 18$ years old) with clinically and radiologically findings compatible with COVID-19 disease from March $1^{\text {st }}$ to April $5^{\text {th }}, 2020$. Exclusion criteria: patients presenting negative PCR for SARS-CoV-2 during the first 7 days from hospital admission, transfer to a hospital not belonging to the HM consortium, lack of data and discharge against medical advice in emergency departments.

Results. One thousand and three hundred thirty-one COVID-19 patients (medium age 66.9 years old; males $n=841$, medium length of hospital stayed 8 days, non-survivors $n=$

\section{Correspondence:}

Pablo Cardinal-Fernández

Intensive care unit coordinator, HM Torrelodones University Hospital

Av. Castillo Olivares, s/n, CP 28250

Torrelodones, Madrid

E-mail: pablocardinal@hotmail.com

*These authors contributed equally to this manuscript.
233) were analyzed. One hundred and fifteen were admitted to intensive care unit (medium length of stay 16 days, invasive mechanical ventilation $n=95$, septic shock $n=37$ and renal replacement therapy $n=17$ ). Age, male gender, leukocytes, platelets, oxygen saturation, chronic therapy with steroids and treatment with hydroxychloroquine/azithromycin were independent factors associated with mortality. The proportion of patients that survive and received tocilizumab and steroids were lesser and higher respectively than those that die, but their association was not significant.

Conclusions. Overall crude mortality rate was $17.5 \%$, rising up to $36.5 \%$ in the subgroup of patients that were admitted to the intensive care unit. Seven factors impact in hospital mortality. No immunomodulatory intervention were associated with in-hospital mortality.

Keywords: SARS-CoV-2; COVID-19; pandemic; epidemiology

\section{Características clínicas y evolutivas de 1.331 pacientes hospitalizados con COVID-19: Cohorte española HM}

Introducción. España es uno de los paises europeos más afectados por la pandemia de COVID-19. Conocer las caracteristicas epidemiológicas y evolutivas permitirá mejorar la comprensión de la enfermedad, evaluar el procedimiento de atención y prepararse para las olas futuras. El objetivo del estudio fue describir las caracteristicas epidemiológicas asociadas a los pacientes hospitalizados por COVID-19. 
Material y métodos. Diseño observacional, multicéntrico y retrospectivo del mundo real realizado en 8 hospitales privados de España. Criterios de inclusión: adultos hospitalizados (edad $\geq 18$ años) con hallazgos clínicos y radiológicos compatibles con enfermedad COVID-19 entre el 1 de marzo al 5 de abril de 2020. Criterios de exclusión: PCR negativa para SARSCoV-2 durante los primeros 7 dias de ingreso hospitalario, traslado a un hospital no perteneciente al consorcio HM, falta de datos y alta contra consejo médico en urgencias.

Resultados. Se analizaron 1.331 pacientes con COVID-19 (edad media 66,9 años; varones $n=841$, estancia media hospitalaria 8 dias, no supervivientes $n=233$ ). Ciento quince ingresaron en la unidad de cuidados intensivos (estancia media 16 dias, ventilación mecánica invasiva $n=95$, choque séptico $n=$ 37 y terapia renal sustitutiva $n=17$ ). La edad, el sexo masculino, los leucocitos, las plaquetas, la saturación de oxígeno, la terapia crónica con esteroides y el tratamiento con hidroxicloroquina / azitromicina fueron factores independientes asociados con la mortalidad.

Conclusiones. La tasa de mortalidad bruta global fue del $17,5 \%$, elevándose hasta el $36,5 \%$ en el subgrupo de pacientes que ingresaron en la unidad de cuidados intensivos. Siete factores impactan en la mortalidad hospitalaria.

Palabras clave: SARS-CoV-2; COVID-19; pandemia; epidemiología

\section{INTRODUCTION}

Last December, the World Health Organization (WHO) received information on a group of pneumonia cases of unknown etiology that were admitted to Hospitals in Wuhan city, China [1]. The pathogen causing this pneumonia was identified as a novel enveloped RNA virus in the family Coronaviridae, named Severe Acute Respiratory Syndrome Coronavirus-2 (SARS-CoV-2) due to its phylogenetic similarity to the previously described SARS-CoV. The clinical presentation associated with SARS-CoV-2 has been named COVID-19. After the initial outbreak in China, the virus spread around the world and was declared a pandemic on day March 11.

Since the first case of COVID-19 reported on January $31^{\text {st }}$, the dramatic growth of cases makes Spain one of the most affected countries worldwide [2]. Recently, a nationwide epidemiological report including COVID-19 hospitalized patients from the outbreak's beginning in Spain was published by Berenguer et al. [3]. This study described the COVID-19 situation at very early stages, reporting only about the first stage of the Spanish outbreak. Other Spanish studies have included low number of patients or specific populations. Thus, the aims of this study were to describe the epidemiological and clinical characteristics of a wide cohort of hospitalized patients with COVID-19 and to identify clinical and laboratory predictors of in-hospital mortality.

\section{MATERIAL AND METHODS}

This real-world, observational, multicenter and retrospec- tive study screened all consecutive patients admitted to the following Spanish hospitals: HM Sanchinarro University Hospital (Madrid), HM Torrelodones University Hospital (Madrid), HM Monteprincipe University Hospital (Madrid), HM Puerta del Sur University Hospital (Madrid), HM Madrid University Hospital (Madrid), HM Valles (Alcala de Henares), HM Regla (Leon) and HM Nuevo-Belen (Galicia). All hospitals belong to HM Hospital Group, a private consortium of general and high complexity hospitals.

Inclusion criteria. Hospitalized adults (age $\geq 18$ years) with clinically and radiologically findings compatible with COVID-19 disease from March $1^{\text {st }}$ to April $5^{\text {th }}, 2020$. For patients who were discharged and subsequently readmitted, only the first episode was considered.

Cases were classified as confirmed or suspected. The former, was considered when a positive SARS-CoV-2 Real Time-Polymerase chain reaction (RT-PCR) result was obtained. The latter, was considered when the RT-PCR was not performed. The decision to include the latter subgroup of patients was based on two reasons: (a) on March $25^{\text {th }}$ 2020, the Spanish Health Secretary recommended not to confirm the COVID-19 when the clinical and radiological presentation was typical and (b), at bedside, these patients were considered and treated as COVID-19.

Exclusion criteria. Patients that presented negative PCR during the first 7 days from hospital admission (this criterion was adopted assuming that the only available evidence was against the SARS-CoV2 diagnosis), transfer to a hospital not belonging to the HM consortium, lack of data and discharge against medical advice at emergency departments.

HM Hospital Group has a unique and centralized Electronic Health Record system denominated HOSMA. All patients, independently of the hospital in which they had been consulted, were registered with a unique identification number. For assistance purposes, at the beginning of the outbreak, HOSMA record was adapted with the aim to allow doctors participating in the patient's assistance (e.g. emergentist, internist, intensivist, etc.) to explicitly register patients with probable or confirmed COVID-19.

Clinical presentation, presence of comorbidities, signs and laboratory findings, admission to intensive care unit (ICU), major complications (requirement of mechanical ventilation, tracheotomy, renal replace therapy, septic shock and hospital death) and pharmacological treatments were retrieved. Follow up was performed until hospital discharge.

Regarding the antiviral therapy, it was always prescribed and administered during the first 24 hours from emergency consultation. Although they were prescribed according to the physician criteria, all treatments were standardized (more than one treatment could be prescribed simultaneously) and included: hydroxychloroquine (400mg BID the first day and then 200mg BID) plus azithromycin (500mg QID) for 5 to 10 days and lopinavir/ritonavir 200/50 BID for 5 to 10 days.

Regarding adjuvant medications, they were also pre- 
scribed according to the physician criteria but were not standardized and the time when were administered varied widely. Thus, for the purpose of this study, some adjustments had to be performed:

- Tocilizumab. The accumulative dose of tocilizumab was calculated as the sum of milligram that each patient received during their hospitalization. Then, it was stratified in: no received, low (0 mg - $600 \mathrm{mg}$ ), intermediate (601 $\mathrm{mg}-1,000 \mathrm{mg}$ ) and high (>1,000 mg) dose.

- Steroid. Firstly, daily dose of steroids was transformed in to equivalent methylprednisolone dose according to equations reported in https://www.rccc.eu/ppc/calculadoras/corticoides.htm (accessed on July 15,2020). Then, all daily methylprednisolone equivalent doses that each patient received were added (accumulative equivalent dose of methylprednisolone). Subsequently, the accumulative equivalent dose of methylprednisolone was divided by the number of days that the patient had received steroids (mean methylprednisolone equivalent dose). Finally, the mean methylprednisolone equivalent dose was stratified as: no steroids, low (1 mg/day - $50 \mathrm{mg} /$ day), intermediate $(51 \mathrm{mg} /$ day - $100 \mathrm{mg} /$ day) and high (>100 mg/day) dose.

- Methylprednisolone bolus. It was defined as a daily dose equivalent methylprednisolone $\geq 150 \mathrm{mg}$.

- Other interventions: vitamin C, colchicine, polyvalent immunoglobulins, cytostatic and montelukast were considered dichotomous (received vs not received).

Tocilizumab and steroids cut-off were defined arbitrarily and before starting the statistical analysis. A posteriori, with the aim to assess the effect of the time evolution, each intervention was stratified in early ( $<3$ days) or late ( $\geq 3$ days) regarding the day of hospital admission in which it were prescribed.

The study was approved by the by the Ethics Committee of HM Group. Written informed consent was waived in light of the urgent need to collect data and absence of intervention.

Statistical analysis. Continuous variables are presented as median and range interquartile (RIQ). Categorical variables as absolute frequency and percentage. Variables with more than $30 \%$ of missing values have not been considered. Multivariable Cox regression analyses was performed to identify factors associated to in-hospital death. The variable effect was expressed as the hazard ratio (HR) and $95 \% \mathrm{Cl}$. A two-sided P $<0.05$ was considered statistically significant.

Statistical analysis was performed with $R$ package. The Strengthening the Reporting of Observational Studies in Epidemiology (STROBE) recommendations and their check list were used to increase the accurate and transparency of the study.

\section{RESULTS}

During the study period, 2,015 patients were assisted at HM Hospitales Group with a clinical suspicion of COVID-19.
From these, 1,956 were hospitalized and 1,331 were analyzed (reasons of exclusion: negative SARS-Cov2 PCR $n=425$, no COVID19 diagnosis $n=112$, translate to a no HM Hospitales center $n=49$, pediatric $n=39$ ). Minor differences between suspected $(n=457)$ and confirmed ( $n=874)$ COVID-19 infection were identified (supplementary table 1).

The peak of daily hospital admissions was on March $18^{\text {th }}$ (91 patients). Then it started to stabilize until the peak of hospitalized patients (March 30, 610 patients) (figure 1).

The clinical and epidemiological characteristics of the population are shown in table 1. Gender distribution was not equal, with a predominance of males (n $841 ; 63.1 \%$ ). The median age was 66.9 years [RIO $55.7 ; 76.8]$. Almost 4 of 10 patients lack co-morbidities. The median of days from the symptoms initiation to hospital admission was 7 [RIO 3.0; 9.0]. The three most frequent symptoms were fever $(n=1,110,83.4 \%)$, dry cough $(n=905 ; 68.0 \%)$ and dyspnea $(n=936 ; 70.3 \%)$. Notably, D dimer and protein $\mathrm{C}$ reactive were elevated in more than $75 \%$ of the patients.

Regarding anti-COVID-19 treatment (table 2, figure 2), most of the patients received hydroxychloroquine/ azithromycin $(n=1,197 ; 89.9 \%)$ and/or lopinavir/ritonavir $(n=956$; $71.8 \%$ ). With respect anti-inflammatory/immunomodulatory treatments (table 2, figure 2), the most frequent pharmacological interventions were the use of steroids ( $n=623 ; 46.8 \%$ ) and tocilizumab $(n=321 ; 21,1 \%)$. Within the group of steroids, almost $40 \%$ received at least one bolus. Other pharmacological interventions (statins, cytostatic, colchicine, polyclonal immunoglobulins, montelukast, ascorbic acid) were prescribed in less than $11 \%$ of the population (table 2).

Regarding severe complications, 115 (8.6\%) patients were admitted to intensive care unit (ICU). Forty-two of them (37.5\%) died. The main findings of ICU-cohort of patients can be appreciated in table 3.

Two hundred thirty-three patient died during the study period (17.5\%). The univariate analysis between dead and survivors' patients are shown in table 1.In multivariate analysis, independent factors associated to in-hospital mortality included older age (HR 1.081 [IC95\%1.064; 1.099]; $p<0.001$ ), male gender (HR 1.417 [IC95\% 1.004; 2.000]; $p=0,047$ ), higher leukocytes count (HR 1.072 [IC95\%1.036; 1.109]; $p<$ 0,001), lower platelets count (HR 0.996 [IC95\% 0.994; 0.998]; $p<0,001$ ), lower oxygen saturation (HR 0.957 [IC95\% 0.941; $0.974] ; \quad p<0,001)$, previous chronic therapy with steroids (HR 3.082 [IC95\% 1.436; 6.612]; $p=0,004)$ and no treatment with hydroxychloroquine/azithromycin (HR 0.303 [IC95\% $0.200 ; 0.460] ; p<0,001$ ) (table 4). Despite early prescription of Lopinavir/Ritonavir and Steroids were associated to an increased survivor rate in the survival analysis (supplementary figure 1), their positive effect disappeared when were included in the COX-regression model.

\section{DISCUSSION}

The present study, evaluating features and outcomes of a 


\begin{tabular}{|c|c|c|c|c|c|}
\hline \multirow{2}{*}{$\begin{array}{l}\text { Table } 1 \\
\text { General featur }\end{array}$} & \multicolumn{5}{|c|}{ Univariate analysis } \\
\hline & & All patients $(n=1,331)$ & Death $(n=233)$ & Alive $(n=1,098)$ & $p$ value \\
\hline PCR confirme & & $874(65.7)$ & $168(72.1)$ & $706(64.3)$ & 0.028 \\
\hline Male ${ }^{*}$ & & $841(63.1)$ & $166(71.2)$ & $675(61.4)$ & 0.006 \\
\hline Age (years)** & & $66.9[55.7 ; 76.8]$ & $79.2[73.0 ; 85.5]$ & $64.0[53.7 ; 73.5]$ & $<0.001$ \\
\hline \multicolumn{6}{|c|}{ Age stratified (years)* } \\
\hline$<40$ & & $72(5.4)$ & $0(0)$ & $72(6.6)$ & \\
\hline $40-60$ & & $362(27.2)$ & $8(3.4)$ & $354(32.2)$ & \\
\hline $61-80$ & & $661(49.7)$ & $122(52.3)$ & $539(49.1)$ & \\
\hline$>80$ & & $236(17.3)$ & $103(44.2)$ & $133(12.1)$ & $<0.001$ \\
\hline Length of hos & tayed (days)** & $8.00[6.00 ; 13.0]$ & $8.00[4.00 ; 13.0]$ & $8.00[6.00 ; 13.0]$ & 0.024 \\
\hline ICU admission & & $115(8.6)$ & $42(18.0)$ & $73(6.6)$ & $<0.001$ \\
\hline \multicolumn{6}{|c|}{ Sign and symptoms at emergency department } \\
\hline Onset of symr & to hospital admission (d) & $7.00[3.00 ; 9.00]$ & $4.00[3.00 ; 7.00]$ & $7.00[4.00 ; 10.0]$ & $<0.001$ \\
\hline Headache ${ }^{*}$ & & $16(1.2)$ & $3(1.3)$ & $13(1.2)$ & 0.751 \\
\hline Anosmia* & & $14(1.1)$ & $2(0.9)$ & $12(1.1)$ & 1.000 \\
\hline Dyspnea* & & $936(70.3)$ & $168(72.1)$ & $768(69.9)$ & 0.565 \\
\hline \multicolumn{6}{|l|}{ Cough * } \\
\hline No & & $344(25.8)$ & $74(31.8)$ & $270(24.6)$ & \\
\hline Cough + re & & $5(0.4)$ & $0(0.0)$ & $5(0.5)$ & \\
\hline Cough $+g r$ & sputum & $8(0.6)$ & $3(1.3)$ & $5(0.5)$ & \\
\hline Cough $+\mathrm{cc}$ & ss sputum & $69(5.2)$ & $14(6.0)$ & $55(5.0)$ & \\
\hline Dry cough & & $905(68.0)$ & $142(60.9)$ & $763(69.4)$ & 0.049 \\
\hline Fever* & & $1110(83.4)$ & $184(79.0)$ & $926(84.3)$ & 0.057 \\
\hline Nausea* & & $68(5.1)$ & $8(3.4)$ & $60(5.5)$ & 0.265 \\
\hline Diarrhea* & & $141(10.6)$ & $13(5.6)$ & $128(11.7)$ & 0.009 \\
\hline Systolic blood & ure $(m m H g)^{* *}$ & $130[117 ; 144]$ & $132[114 ; 147]$ & $130[118 ; 144]$ & 0.939 \\
\hline Diastolic bloo & ure $(m m H g)^{* *}$ & $76.0[67.0 ; 84.0]$ & $73.0[63.5 ; 79.0]$ & $76.0[69.0 ; 84.0]$ & $<0.001$ \\
\hline Heart rate (bp & & $90.0[80.0 ; 102.0]$ & $90.0[80.0 ; 102.0]$ & $90.0[80.0 ; 102.0]$ & 0.970 \\
\hline Temperature ( & & $36.7[36.3 ; 37.4]$ & $36.8[36.3 ; 37.4]$ & $36.7[36.3 ; 37.4]$ & 0.703 \\
\hline Oxygen satur & $\%)^{* *}$ & $94.0[90.0 ; 96.0]$ & $90.0[82.0 ; 94.0]$ & $94.0[91.0 ; 96.0]$ & $<0.001$ \\
\hline \multicolumn{6}{|c|}{ Comorbidities } \\
\hline \multicolumn{6}{|c|}{ Number of comorbidities } \\
\hline 0 & & $528(39.7)$ & $47(20.2)$ & $481(43.8)$ & \\
\hline 1 & & $374(28.1)$ & $71(30.5)$ & $303(27.6)$ & \\
\hline 2 & & $250(18.7)$ & $54(23.2)$ & $196(17.8)$ & \\
\hline 3 & & $121(9.1)$ & $39(16.7)$ & $82(7.5)$ & \\
\hline 4 & & $40(3.0)$ & $11(4.7)$ & $29(2.6)$ & \\
\hline 5 & & $10(0.8)$ & $6(2.6)$ & $4(0.4)$ & \\
\hline 6 & & $7(0.5)$ & $4(1.7)$ & $3(0.3)$ & \\
\hline 7 & & $1(0.1)$ & $1(0.4)$ & $0(0.0)$ & $<0.001$ \\
\hline
\end{tabular}




\begin{tabular}{|c|c|c|c|c|c|}
\hline Table 1 & \multicolumn{5}{|c|}{ Univariate analysis (cont). } \\
\hline \multicolumn{2}{|c|}{ Comorbidities } & All patients $(n=1,331)$ & Death $(n=233)$ & Alive $(n=1,098)$ & $p$ value \\
\hline \multicolumn{2}{|c|}{ Malignancy * } & $56(4.2)$ & $21(9.0)$ & $35(3.2)$ & $<0.001$ \\
\hline \multicolumn{2}{|l|}{ Diabetes* $^{*}$} & $167(12.5)$ & $47(20.2)$ & $120(10.9)$ & $<0.001$ \\
\hline \multicolumn{2}{|c|}{ Inmunosupression* } & $8(0.6)$ & $1(0.4)$ & $7(0.6)$ & 1.000 \\
\hline \multicolumn{2}{|l|}{ HIV/AIDS * } & $1(0.1)$ & $0(0.0)$ & $1(0.1)$ & 1.000 \\
\hline \multicolumn{2}{|c|}{ Thyroid disease ${ }^{*}$} & $99(7.4)$ & $22(9.4)$ & $77(7.0)$ & 0.252 \\
\hline \multicolumn{2}{|l|}{ Dislipemia* } & $274(20.6)$ & $57(24.5)$ & $217(19.8)$ & 0.128 \\
\hline \multicolumn{2}{|l|}{ Smoking* ${ }^{*}$} & $54(4.1)$ & $10(4.3)$ & $44(4.1)$ & 0.986 \\
\hline \multicolumn{2}{|c|}{ Chronic obstructive pulmonary disease ${ }^{*}$} & $63(4.7)$ & $26(11.2)$ & $37(3.4)$ & $<0.001$ \\
\hline \multicolumn{2}{|l|}{ Asthma* } & $52(3.9)$ & $8(3.4)$ & $44(4.0)$ & 0.822 \\
\hline \multicolumn{2}{|c|}{ Neurologic disease* (Stroke, TIA or dementia) } & $52(3.9)$ & $29(12.4)$ & $23(2.1)$ & $<0.001$ \\
\hline \multicolumn{2}{|c|}{ High blood pressure $(\mathrm{mmHg})^{* *}$} & $500(37.6)$ & $126(54.1)$ & $374(34.1)$ & $<0.001$ \\
\hline \multicolumn{2}{|c|}{ Acute coronary disease ${ }^{*}$} & $93(7.0)$ & $30(12.9)$ & $63(5.7)$ & $<0.001$ \\
\hline \multicolumn{2}{|c|}{ Alcohol abuse ${ }^{*}$} & $25(1.9)$ & $6(2.6)$ & $19(1.7)$ & 0.422 \\
\hline \multicolumn{2}{|c|}{ Chronic kidney disease* } & $39(2.9)$ & $14(6.0)$ & $25(2.3)$ & 0.004 \\
\hline \multicolumn{2}{|c|}{ Chronic liver disease ${ }^{*}$} & $14(1.0)$ & $4(1.7)$ & $10(0.9)$ & 0.285 \\
\hline \multicolumn{6}{|c|}{ Chronic Medication } \\
\hline \multicolumn{2}{|l|}{ Statins* } & $233(17.5)$ & $49(21.0)$ & $184(16.8)$ & 0.143 \\
\hline \multicolumn{2}{|c|}{ Anticoagulants ${ }^{*}$} & $82(6.2)$ & $30(12.9)$ & $52(4.7)$ & $<0.001$ \\
\hline \multicolumn{2}{|c|}{ Antiagregants $^{*}$} & $123(9.2)$ & $35(15.0)$ & $88(8.0)$ & 0.001 \\
\hline \multicolumn{2}{|l|}{ IECA/ARAII* } & $328(24.6)$ & $70(30.0)$ & $258(23.5)$ & 0.043 \\
\hline \multicolumn{2}{|c|}{ Beta blockers* } & $150(11.3)$ & $43(18.5)$ & $107(9.7)$ & $<0.001$ \\
\hline \multicolumn{2}{|l|}{ Diuretics ${ }^{*}$} & $103(7.7)$ & $37(15.9)$ & $66(6.0)$ & $<0.001$ \\
\hline \multicolumn{2}{|c|}{ Thyroid replacement hormones* } & $96(7.2)$ & $20(8.6)$ & $76(6.9)$ & 0.452 \\
\hline \multicolumn{2}{|c|}{ Oral steroids* } & $21(1.6)$ & $10(4.3)$ & $11(1.0)$ & 0.001 \\
\hline \multicolumn{2}{|c|}{ Inhaled steroids* } & $48(3.6)$ & $12(5.2)$ & $36(3.3)$ & 0.231 \\
\hline \multicolumn{2}{|c|}{ Inhaled b2 agonist* } & $33(2.5)$ & $6(2.6)$ & $27(2.5)$ & 1.000 \\
\hline \multicolumn{2}{|c|}{ Inhaled antimuscarinic ${ }^{*}$} & $30(2.3)$ & $9(3.9)$ & $21(1.9)$ & 0.114 \\
\hline
\end{tabular}

${ }^{*} \mathrm{n}(\%)$. ${ }^{* *}$ p50 [p25; 075]. ICU: intensive care unit

large cohort of hospitalized COVID-19 patients, highlights several interesting clinical points about the first pandemic wave in Spain.

First, despite the dramatic increasing initial flow of hospital admissions for COVID-19 in the first 3 weeks of the outbreak with 6 times more in the third week (peak of the pandemic) compared to the first week of the outbreak (figure 1), more than $80 \%$ of the patients survived.

Second, less than 9\% of hospitalized patients were admitted to ICU. Critically ill patients had much higher mortality (close to 40\%) and complications such as invasive mechanical ventilation and septic shock, with longer stay at ICU and under mechanical ventilation than previous report from
non-COVID19 patients[4]. In this setting, several factors were independently associated to mortality: older age, male gender, previous chronic use of systemic steroids, high leukocytes count [at emergency], low platelets count [at emergency], low oxygen saturation [at emergency] and early treatment with hydroxychloroquine/azithromycin. All anti-inflammatory/immunomodulate interventions have a neutral effect.

Mortality rate in hospitalized COVID19 patients has been described with a wide range, from $13.6 \%$ [5] to $28.0 \%$ [3]. Our rate $(17.5 \%)$ is intermediate and similar to other reports from Spain [6], others countries [7] and an international meta-analysis that included 58 studies with 122,191 patients [8]. Indeed, the mortality rate from those that were admitted to ICU was also very similar to international reports [9]. We have identified 


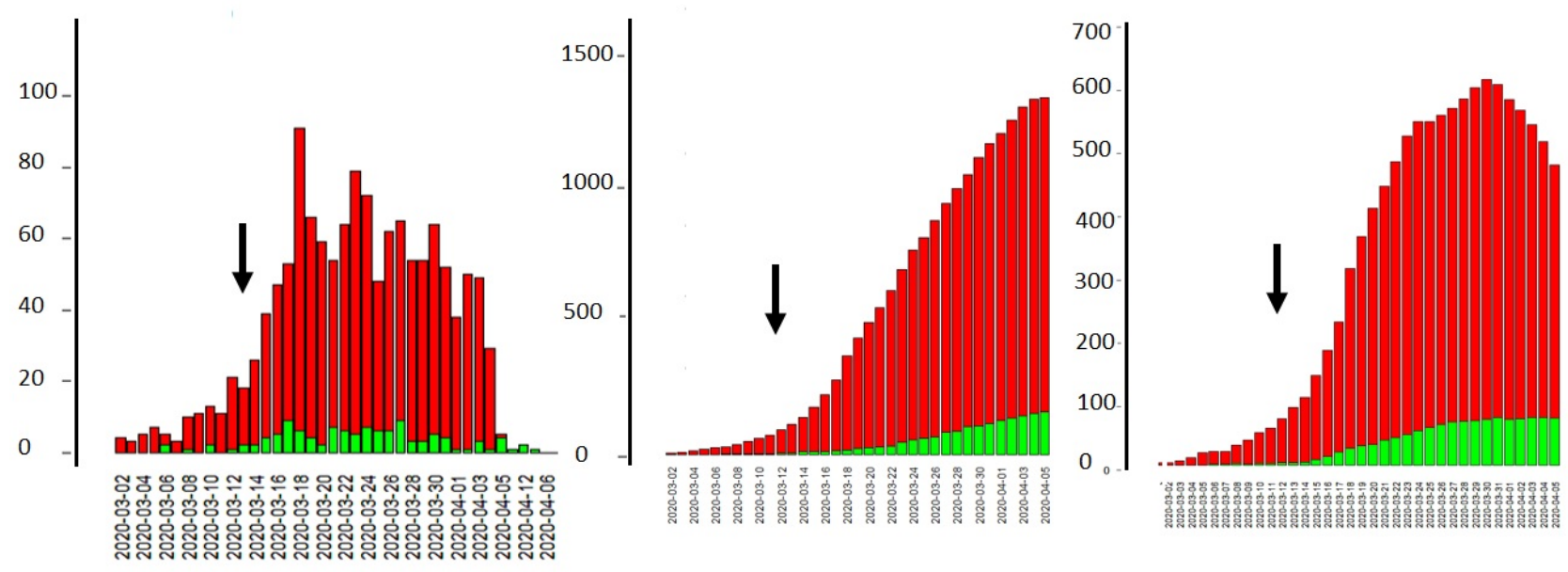

\begin{tabular}{l|l} 
Figure 1 & Hospital admission per day (absolute and accumulative frequency) and patients at hospital each day
\end{tabular}

Right: absolute frequency of hospital admission per day. Middle: accumulative frequency of admission. Left: patients at hospital per day (red: all patients, green: patients admitted to the intensive care unit) Red: all patients; green: ICU admissions. Arrow: Spanish's lockdown beggining.

seven factors independently associated with the mortality. Five of them (age, gender, leukocytes, platelets and oxygen saturation) have been reported and widely analyzed in other studies $[3,10,11]$. Thus, we will focus the discussion in the others two factors: previous chronic use of systemic steroid and treatment with hydroxychloroquine/azithromycin.

Our study reported that chronic use of steroid is associated to increased risk of hospital mortality. The evidence to support this association is scarce. However, we speculate that could be explained, at least, by two factors. Firstly, it has been described that chronic steroid therapy increases the risk of developing infections, including those produced by virus [12]. Secondly, it could be possible that steroid being a confounding factor and the real risk factor could be the disease that requires the steroids. In favor of this proposal is the fact that several chronical diseases that commonly require steroids (e.g. asthma, COPD, malignancies, etc.) were overrepresented in the subgroup of died patient. On the other hand, until the recent evidence reported by well-designed RCTs[13, 14] and meta-analysis[15], the effect of steroid administered during hospital stayed had been widely debated with observatory studies in favor $[16,17]$, against $[18,19]$ and neutral [20]. Our study did not find an association, neither with steroid at different doses nor with boluses. Although this result is online with some previously mentioned, we have to be very cautiously at their interpretation as several studies, with more evidence hierarchy, support their prescription at low doses, for a limited period of time and in patient with moderate and severe disease [13-15]. Additionally, pharmacological effects of steroids depend on the daily dose and the treatment length, and it is problematic to measure the concept of "chronic use" of corticosteroids in every patient's medical history, due to this therapeutic heterogeneity. At the beginning of the pandemic a small study proposed that hydroxychloroquine/azithromycin could be an effective therapy for improving the viral clearance [21]. Then, their prescription off-label increased abruptly which explain that $80 \%$ of our patients received this treatment. In this setting, several observational studies, like in our cohort, have reported that this combination could improve the outcome in COVID19 patients. However, several RCTs and meta-analysis have suggested the futility of this intervention $[22,23]$. Regarding the tocilizumab, we did not find a significant association between it and hospital mortality, which is online with several RCTs. Indeed, the preliminary report of the Evaluate the Efficacy and Safety of Tocilizumab in Hospitalized Participants With COVID-19 Pneumonia (EMPACTA) mentioned that 28-day mortality was not affected by this IL-6 receptor blocker. It is obvious that interpreting the evidence to support the COVID-19 treatments is a real challenge since there is an evident disagreement between observational and RCTs studies [24]. This controversy should not be a surprise as it have happened with several intervention in the past and may be explained by several reasons; probably the three most relevant are the assignment bias typically associated to observatory studies, the better control of confounding and the more homogenous population in RCT compared to observational studies [24]. Every clinician should always remind that evidence from RCTs is considered the gold standard for establishing causality, giving the best assurance that the association between exposure and outcome is not related to confounding. However, observational studies can provide accurate evidence from real world data [25].

Regarding the clinical presentation at emergency department, the three most frequent symptoms in our study were fever, cough, and dyspnea, which is in line with other reports $[7,26]$. Although COVID19 is usually associated to respiratory symptoms, it is important to point out that more than $10 \%$ of 


\begin{tabular}{|c|c|c|c|c|c|}
\hline \multirow{2}{*}{\multicolumn{2}{|c|}{\begin{tabular}{c|c} 
Table 2 & Univariate analysis \\
Laboratory findings at emergency department
\end{tabular}}} & \multirow[b]{2}{*}{ All patients $(n=1,331)$} & \multirow[b]{2}{*}{ Death $(n=233)$} & \multirow[b]{2}{*}{ Alive $(n=1,098)$} & \multirow[b]{2}{*}{$p$ value } \\
\hline & & & & & \\
\hline Hemoglobin (g & & $14.1[13.1 ; 15.2]$ & $13.8[12.3 ; 15.2]$ & $14.2[13.1 ; 15.2]$ & 0.002 \\
\hline White Blood c & unt $\left.\times 10^{9} / L\right)^{* *}$ & $6.33[4.91 ; 8.51]$ & $7.15[5.18 ; 10.1]$ & $6.21[4.85 ; 8.23]$ & $<0.001$ \\
\hline Neutrophil (co & $10^{9} / \mathrm{LL}^{* *}$ & $4.69[3.33 ; 6.81]$ & $5.76[3.77 ; 8.45]$ & $4.58[3.28 ; 6.41]$ & $<0.001$ \\
\hline Lymphocyte (c & $\left.x 10^{9} / L\right)^{* *}$ & $1.00[0.71 ; 1.35]$ & $0.77[0.52 ; 1.19]$ & $1.02[0.76 ; 1.39]$ & $<0.001$ \\
\hline Monocyte (col & $\left.10^{9} / \mathrm{L}\right)^{* *}$ & $0.45[0.32 ; 0.63]$ & $0.47[0.30 ; 0.68]$ & $0.44[0.32 ; 0.63]$ & 0.980 \\
\hline Basophils (cou & $\left.0^{9} / \mathrm{L}\right)^{* *}$ & $0.01[0.01 ; 0.02]$ & $0.01[0.01 ; 0.03]$ & $0.01[0.01 ; 0.02]$ & 0.714 \\
\hline Eosinophil (co & $10^{9} / \mathrm{LL} *$ & $0.00[0.00 ; 0.02]$ & $0.00[0.00 ; 0.02]$ & $0.01[0.00 ; 0.02]$ & 0.044 \\
\hline Platelet (coun & (L) $)^{* *}$ & $192[154 ; 245]$ & $174[139 ; 225]$ & $196[156 ; 249]$ & $<0.001$ \\
\hline Glucose $(\mathrm{mg} / \mathrm{d}$ & & $116[104 ; 136]$ & $126[110 ; 155]$ & $114[103 ; 133]$ & $<0.001$ \\
\hline Protrombine a & $y(\%)^{* *}$ & $76.0[68.0 ; 85.0]$ & $73.0[61.8 ; 82.0]$ & $78.0[69.0 ; 86.0]$ & $<0.001$ \\
\hline Activated part & romboplastin time $(s){ }^{* *}$ & $32.2[30.0 ; 34.8]$ & $32.5[29.7 ; 35.7]$ & $32.1[30.0 ; 34.5]$ & 0.215 \\
\hline Total bilirrubin & $g / d l)^{* *}$ & $0.46[0.34 ; 0.62]$ & $0.51[0.35 ; 0.76]$ & $0.45[0.34 ; 0.60]$ & 0.052 \\
\hline Aspartate ami & nsferase $(\mathrm{U} / \mathrm{L})^{* *}$ & $36.0[26.0 ; 55.8]$ & $39.8[27.1 ; 62.0]$ & $35.0[25.3 ; 53.3]$ & 0.005 \\
\hline Alanine amino & ferase $(U / L)^{* *}$ & $28.4[18.0 ; 46.0]$ & $24.4[16.0 ; 41.9]$ & $29.1[19.0 ; 46.9]$ & 0.001 \\
\hline International & alized ratio ${ }^{* *}$ & $1.19[1.11 ; 1.30]$ & $1.23[1.15 ; 1.38]$ & $1.19[1.11 ; 1.28]$ & $<0.001$ \\
\hline D dimer (mg/L & & $724[448 ; 1178]$ & $1173[732 ; 2205]$ & $658[424 ; 1060]$ & $<0.001$ \\
\hline Lactate dehyd & $\operatorname{ase}(\mathrm{U} / \mathrm{L})^{* *}$ & $554[430 ; 714]$ & $680[506 ; 959]$ & $537[421 ; 674]$ & $<0.001$ \\
\hline Sodium (mmo & & $136[134 ; 139]$ & $136[134 ; 139]$ & $136[134 ; 139]$ & 0.218 \\
\hline Potasium (mm & & $4.17[3.87 ; 4.50]$ & $4.27[3.95 ; 4.73]$ & $4.16[3.86 ; 4.47]$ & 0.002 \\
\hline C reactive prot & $n g / d L) * *$ & $79.1[33.9 ; 152]$ & $127[68.9 ; 219]$ & $71.3[30.8 ; 142]$ & $<0.001$ \\
\hline Blood urea nit & $(\mathrm{mg} / \mathrm{dl})^{* *}$ & $32.7[25.0 ; 45.8]$ & $47.0[36.8 ; 71.5]$ & $30.2[24.0 ; 41.0]$ & $<0.001$ \\
\hline Creatinine $(\mathrm{mg}$ & & $0.92[0.74 ; 1.09]$ & $1.06[0.85 ; 1.31]$ & $0.89[0.73 ; 1.05]$ & $<0.001$ \\
\hline \multicolumn{6}{|c|}{ Pharmacological treatments during hospitalization } \\
\hline Tocilizumab* & & $321(24.1)$ & $76(32.6)$ & $245(22.3)$ & $<0.001$ \\
\hline \multicolumn{6}{|l|}{ Tocilizumab ${ }^{\mathrm{a}, *}$} \\
\hline № & & 1010 (75.9) & $157(67.4)$ & $853(77.7)$ & \\
\hline $0-599 \mathrm{mg}$ & & $80(6.0)$ & $21(9.0)$ & $59(5.4)$ & \\
\hline $600-999 \mathrm{mg}$ & & $213(16.0)$ & $42(18.0)$ & $171(15.6)$ & \\
\hline$\geq 1000 \mathrm{mg}$ & & $28(2.1)$ & $13(5.6)$ & $15(1.3)$ & $<0.001$ \\
\hline Steroids* & & $623(46.8)$ & $153(11.5)$ & $470(35.3)$ & $<0.001$ \\
\hline \multicolumn{6}{|l|}{ Steroids ${ }^{b, *}$} \\
\hline No & & 708 (53.2) & $80(34.3)$ & $628(57.2)$ & \\
\hline $0-49 \mathrm{mg} / \mathrm{da}$ & & $144(10.8)$ & $27(11.6)$ & $117(10.6)$ & \\
\hline $50-99 \mathrm{mg} / \mathrm{d}$ & & $231(17.3)$ & $44(18.9)$ & $187(17.0)$ & \\
\hline$\geq 100 \mathrm{mg} / \mathrm{da}$ & & $248(18.6)$ & $82(35.2)$ & $166(15.1)$ & $<0.001$ \\
\hline Steroids bolus & & 249 (18.7) & 75 (32.2) & $174(15.8)$ & $<0.001$ \\
\hline Hidroxicloroqu & & 1197 (89.9) & $180(77.2)$ & 1017 (92.8) & $<0.001$ \\
\hline Lopinavir/ritor & & $956(71,8)$ & 147 (63.1) & 809 (73.6) & \\
\hline Cytostatic $^{*}$ & & $28(2.1)$ & $6(2.6)$ & $22(2.0)$ & 0.763 \\
\hline Colchicine ${ }^{*}$ & & $38(2.8)$ & $5(2.1)$ & $33(3.0)$ & 0.618 \\
\hline Polyclonal inm & lobulines* & $13(1.0)$ & $8(3.4)$ & $5(0.4)$ & $<0.001$ \\
\hline Montelukast* & & $78(5.9)$ & $11(4.7)$ & $67(6.1)$ & 0.508 \\
\hline Ascorbic acid* & & $30(2.3)$ & $13(5.6)$ & $17(1.5)$ & $<0.001$ \\
\hline HMG-CoA* & & $144(10.8)$ & $36(15.4)$ & $108(9.8)$ & 0.017 \\
\hline
\end{tabular}

${ }^{\mathrm{a} A c c u m u l a t i v e ~ d o s e ; ~}{ }^{\mathrm{b} M e a n}$ methylprednisolone equivalent dose per day of treatment HMG-CoA: 3-hidroxi-3-metil-glutaril-CoA reductase ${ }^{*}$ dichotomous variable and $\mathrm{n}(\%)$. ${ }^{*} \mathrm{p} 50$ [p25; 075]. 

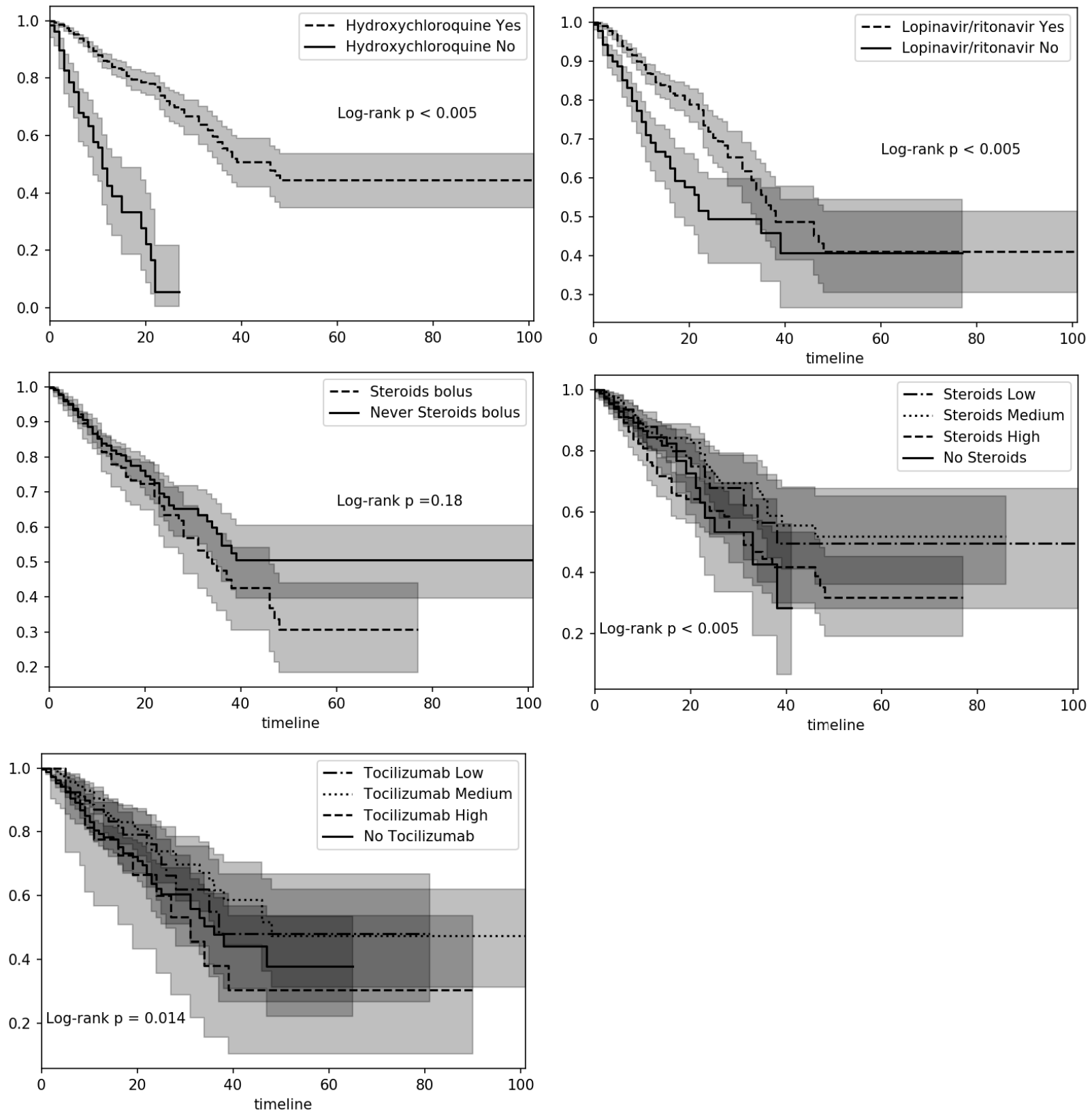

Figure 2 Pharmacological interventions (survival analysis)

our cohort presented diarrhea (sometimes as initial and even only symptom) which could difficult the diagnosis if the physician is not aware about this fact. Likewise, this frequent symptom is over-represented in the subgroup of survivors patients which may reflect any effect on the virus infection pathophysiology and transmissibility.

The number of days with symptoms at hospital admission was greater in the surviving group with respect died patients.
We speculate that it could be explained by a faster evolution in more aggressive infection cases. Further studies should clarify this issue.

Almost 9\% of hospitalized patients developed severe clinical deterioration and had to be admitted to the ICU, with almost double mortality rate with respect non-ICU patients. Likewise, this subgroup of patients has features different from non-COVID19 patients [27]. For example, the ICU stayed and 


\begin{tabular}{|c|c|c|c|c|c|}
\hline \multirow[t]{2}{*}{ Table 3} & \multicolumn{5}{|c|}{ Univariate analysis of patients admitted to the intensive care unit } \\
\hline & & All patients $(n=115)$ & Death $(n=42)$ & Alive $(n=73)$ & $p$-value \\
\hline \multicolumn{2}{|l|}{ Days at ICU** } & $16.0[9.00 ; 31.0]$ & $12.0[7.25 ; 30.5]$ & $20.0[10.0 ; 31.0]$ & 0.106 \\
\hline \multicolumn{2}{|c|}{ Days from hospital to ICU admission** } & $3.00[1.00 ; 4.50]$ & $3.00[2.00 ; 6.00]$ & $3.00[1.00 ; 4.00]$ & 0.079 \\
\hline \multicolumn{2}{|c|}{ Invasive mechanical ventilation } & $95(82.6)$ & $36(85.7)$ & $59(80.8)$ & 0.681 \\
\hline \multicolumn{2}{|c|}{ Days of invasive mechanical ventilation** } & $16.5[9.00 ; 27.8]$ & $14.0[8.50 ; 28.0]$ & $18.0[9.00 ; 27.5]$ & 0.584 \\
\hline \multicolumn{2}{|l|}{ Tracheotomy* } & $55(56.1)$ & $17(47.2)$ & $38(61.3)$ & 0.254 \\
\hline \multicolumn{2}{|c|}{ Days from ICU admission to tracheostomy* } & $14.0[12.0 ; 17.0]$ & $15.0[12.0 ; 16.0]$ & $14.0[12.0 ; 17.0]$ & 0.666 \\
\hline \multicolumn{2}{|l|}{ Septic shock* } & $37(32.2)$ & $23(54.8)$ & $14(19.2)$ & $<0.001$ \\
\hline \multicolumn{2}{|c|}{ Renal replace therapy* } & $17(14.8)$ & $9(21.4)$ & $8(11.0)$ & 0.211 \\
\hline
\end{tabular}

\begin{tabular}{l|cc}
\hline Table 4 & Cox model for hospital mortality & \\
& & \\
\hline & Hazard ratio $(I C 95 \%)$ & p value \\
\hline Age (years) & $1.081(1.064 ; 1.099)$ & $<0.001$ \\
\hline Male & $1.417(1.004 ; 2.000)$ & 0.047 \\
\hline Systemic steroids (chronic medication) & $3.082(1.436 ; 6.612)$ & 0.004 \\
\hline Leukocytes at emergency (count x $\left.10^{9}\right)$ & $1.072(1.036 ; 1.109)$ & $<0.001$ \\
\hline Platelets at emergency (count x $\left.10^{9} / L\right)$ & $0.996(0.994 ; 0.998)$ & $<0.001$ \\
\hline Oxygen saturation at emergency $(\%)$ & $0.957(0.941 ; 0.974)$ & $<0.001$ \\
\hline Hydroxychloroquine/azithromycin & $0.303(0.200 ; 0.460)$ & $<0.001$ \\
\hline
\end{tabular}

proportion of advanced life support therapies (invasive mechanical ventilation, septic shock and renal replace therapy) we have reported is similar than described in other studies; but longer and higher respectively than non-COVID19 patients [4, 28]. We would like to point out the high proportion of patients that required a tracheostomy and the time elapsed from intubation and to the procedure (in 75\% of the patients the tracheostomy was performed after the 12 day from intubation) is online with Spain's guidelines [29]. All this information is of paramount importance at the moment of informing patient's relatives and organizes the ICU assistance.

Our study has several limitations. First, it is retrospective study. However, its impact should be limited as all information was registered prospectively in a centralized and unique database. Indeed, all physicians were trained to register COVID-19 patients at the moment they were assisting them. Secondly, we could not consider some potentially relevant clinical, laboratory and imagen variables (e.g. respiratory frequency, interleukin 6 levels, thorax x-ray, etc.), although the lack of these parameters does not invalid results we are reporting. Thirdly, for analyzing steroids and tocilizumab we had to perform some equivalences that may interfere with the accuracy of the final result. Fourthly, we had to face a new infection whose treatment was unknown and changing; indeed, the same patients could receive more than one intervention, simultaneously or consecutively. Fifth, probably the most important limitation: our study is descriptive, so it suffers from indication bias and lacks of a comparator, which limits the conclusions. This is particularly evident in the case of antimalarial medications and steroids, which protective effect has been questioned by several RCTs.

On the other hand, this study has several strengths. Firstly, it includes a large sample size of consecutively patients which accurately reflect the reality of the first outbreak in Spain. Indeed, we have followed up all patients until their hospital discharge. This fact is not common in several recognized observational studies $[3,7,30]$. Secondly, the fact that all hospitals belong to the same group and share all the information and clinical practices allow us to reduce the traditional variability seen in most of multicenter studies.

As a summary, here we report a mortality rate of 17.5\%. in a large cohort of hospitalized patients in the first Spanish pandemic wave. This value rises up to $36.2 \%$ in the patients 
admitted to ICU admission. We have identified seven factors associated to in-hospital mortality, with the observation that hydroxychloroquine could be an effective treatment, associated with lower mortality. This finding should be considered with caution as several RCTs have questioned its utility.

\section{FUNDING}

None to declare

\section{CONFLICT OF INTEREST}

all authors declare no conflict of interest

\section{REFERENCES}

1. Zhu N, Zhang D, Wang W, Li X, Yang B, Song J, et al. A Novel Coronavirus from Patients with Pneumonia in China, 2019. N Engl J Med. 2020;382(8):727-33. DOI: 10.1056/NEJMoa2001017

2. Tarraso Castillo J, Posadas Blazquez TJ, Lahosa Cordoba C, Signes-Costa J. COVID-19: New disease, new manifestations. Arch Bronconeumol. 2020;56(12):825-6. DOI: 10.1016/j.arbres.2020.07.007

3. Berenguer J, Ryan P, Rodriguez-Bano J, Jarrin I, Carratala J, Pachon J, et al. Characteristics and predictors of death among 4,035 consecutively hospitalized patients with COVID-19 in Spain. Clin Microbiol Infect. 2020. DOI: 10.1016/j.cmi.2020.07.024

4. Esteban A, Anzueto A, Frutos F, Alia I, Brochard L, Stewart TE, et al. Characteristics and outcomes in adult patients receiving mechanical ventilation: a 28-day international study. JAMA. 2002;287(3):34555. DOI: 10.1001/jama.287.3.345

5. Gil-Rodrigo A, Miro O, Pinera P, Burillo-Putze G, Jimenez S, Martin $A$, et al. Analysis of clinical characteristics and outcomes in patients with COVID-19 based on a series of 1000 patients treated in Spanish emergency departments. Emergencias. 2020;32(4):233-41.

6. Iftimie $S$, Lopez-Azcona AF, Vicente-Miralles M, Descarrega-Reina $R$, Hernandez-Aguilera A, Riu F, et al. Risk factors associated with mortality in hospitalized patients with SARS-CoV-2 infection. A prospective, longitudinal, unicenter study in Reus, Spain. PLoS One. 2020;15(9):e0234452. DOI: 10.1371/journal.pone.0234452

7. Richardson $\mathrm{S}$, Hirsch JS, Narasimhan M, Crawford JM, McGinn T, Davidson KW, et al. Presenting Characteristics, Comorbidities, and Outcomes Among 5700 Patients Hospitalized With COVID-19 in the New York City Area. JAMA. 2020;323(20):2052-9. DOI: 10.1001/ jama.2020.6775

8. Noor FM, Islam MM. Prevalence and Associated Risk Factors of Mortality Among COVID-19 Patients: A Meta-Analysis. J Community Health. 2020. DOI: 10.1007/s10900-020-00920-x

9. Zhou S, Yang Y, Zhang X, Li Z, Liu X, Hu C, et al. Clinical Course of 195 Critically III COVID-19 Patients: A Retrospective Multicenter Study. Shock. 2020;54(5):644-51. DOI: 10.1097/SHK.0000000000001629

10. Hajifathalian K, Sharaiha RZ, Kumar S, Krisko T, Skaf D, Ang B, et al. Development and external validation of a prediction risk model for short-term mortality among hospitalized U.S. COVID-19 patients: A proposal for the COVID-AID risk tool. PLoS One. 2020;15(9):e0239536. D0I: 10.1371/journal.pone.0239536

11. Posso $M$, Comas $M$, Roman $M$, Domingo L, Louro J, Gonzalez $C_{\text {, et }}$ al. Comorbidities and Mortality in Patients With COVID-19 Aged 60 Years and Older in a University Hospital in Spain. Arch Bronconeumol. 2020;56(11):756-8. D0I: 10.1016/j.arbres.2020.06.012

12. Youssef J, Novosad SA, Winthrop KL. Infection Risk and Safety of Corticosteroid Use. Rheum Dis Clin North Am. 2016;42(1):157-76, ix-x. DOI: 10.1016/j.rdc.2015.08.004

13. Group RC, Horby P, Lim WS, Emberson JR, Mafham M, Bell JL, et al. Dexamethasone in Hospitalized Patients with Covid-19 - Preliminary Report. N Engl J Med. 2020. DOI: 10.1056/NEJMoa2021436

14. Tomazini BM, Maia IS, Cavalcanti AB, Berwanger O, Rosa RG, Veiga $V C$, et al. Effect of Dexamethasone on Days Alive and Ventilator-Free in Patients With Moderate or Severe Acute Respiratory Distress Syndrome and COVID-19: The CoDEX Randomized Clinical Trial. JAMA. 2020;324(13):1307-16. DOI: 10.1001/jama.2020.17021

15. Group WHOREAfC-TW, Sterne JAC, Murthy S, Diaz JV, Slutsky AS, Villar J, et al. Association Between Administration of Systemic Corticosteroids and Mortality Among Critically III Patients With COVID-19: A Meta-analysis. JAMA. 2020;324(13):1330-41. D0I: 10.1001/jama.2020.17023

16. Fadel R, Morrison AR, Vahia A, Smith ZR, Chaudhry Z, Bhargava P, et al. Early Short Course Corticosteroids in Hospitalized Patients with COVID-19. Clin Infect Dis. 2020. DOI: 10.1093/cid/ciaa601

17. Fernandez-Cruz A, Ruiz-Antoran B, Munoz-Gomez A, Sancho-Lopez A, Mills-Sanchez P, Centeno-Soto GA, et al. A Retrospective Controlled Cohort Study of the Impact of Glucocorticoid Treatment in SARS-CoV-2 Infection Mortality. Antimicrob Agents Chemother. 2020;64(9). DOI: 10.1128/AAC.01168-20

18. Chen $X$, Zhu B, Hong W, Zeng J, He $X$, Chen J, et al. Associations of clinical characteristics and treatment regimens with the duration of viral RNA shedding in patients with COVID-19. Int J Infect Dis. 2020;98:252-60. DOI: 10.1016/j.ijid.2020.06.091

19. Giacobbe DR, Battaglini D, Ball L, Brunetti I, Bruzzone B, Codda G, et al. Bloodstream infections in critically ill patients with COVID-19. Eur J Clin Invest. 2020;50(10):e13319. D0I: 10.1111/eci.13319

20. Zheng C, Wang J, Guo H, Lu Z, Ma Y, Zhu Y, et al. Risk-adapted Treatment Strategy For COVID-19 Patients. Int J Infect Dis. 2020;94:74-7. DOI: 10.1016/j.ijid.2020.03.047

21. Gautret $P$, Lagier JC, Parola $P$, Hoang VT, Meddeb L, Mailhe $M$, et al. Hydroxychloroquine and azithromycin as a treatment of COVID-19: results of an open-label non-randomized clinical trial. Int J Antimicrob Agents. 2020;56(1):105949. D0I: 10.1016/j.ijantimicag.2020.105949

22. Cavalcanti AB, Zampieri FG, Rosa RG, Azevedo LCP, Veiga VC, Avezum $A$, et al. Hydroxychloroquine with or without Azithromycin in Mild-to-Moderate Covid-19. N Engl J Med. 2020. DOI: 10.1056/NEJMoa2019014

23. Kashour Z, Riaz M, Garbati MA, AIDosary O, Tlayjeh H, Gerberi D, et al. Efficacy of chloroquine or hydroxychloroquine in COVID-19 patients: a systematic review and meta-analysis. J Antimicrob Chem- 
other. 2020. D0I: 10.1093/jac/dkaa403

24. Sancho M, Muniz J, Cardinal Fernandez PA. Tocilizuman in COVID-19 patients. Med Clin (Barc) - accepted. 2020.

25. Tlayjeh $\mathrm{H}$, Mhish $\mathrm{OH}$, Enani MA, Alruwaili $A$, Tleyjeh $\mathrm{R}$, Thalib $L$, et al. Association of corticosteroids use and outcomes in COVID-19 patients: A systematic review and meta-analysis. J Infect Public Health. 2020;13(11):1652-63. DOI: 10.1016/j.jiph.2020.09.008

26. Zhu J, Zhong Z, Ji P, Li H, Li B, Pang J, et al. Clinicopathological characteristics of 8697 patients with COVID-19 in China: a meta-analysis. Fam Med Community Health. 2020;8(2). DOI: 10.1136/ fmch-2020-000406

27. Richards-Belle A, Orzechowska I, Gould DW, Thomas K, Doidge JC, Mouncey PR, et al. COVID-19 in critical care: epidemiology of the first epidemic wave across England, Wales and Northern Ireland. Intensive Care Med. 2020;46(11):2035-47. DOI: 10.1007/s00134020-06267-0

28. Huang $C$, Wang $Y, L i X$, Ren $L$, Zhao J, Hu Y, et al. Clinical features of patients infected with 2019 novel coronavirus in Wuhan, China. Lancet. 2020;395(10223):497-506. DOI: 10.1016/S01406736(20)30183-5

29. Martin Delgado MC, Aviles-Jurado FX, Alvarez Escudero J, Aldecoa Alvarez-Santuyano C, de Haro Lopez C, Diaz de Cerio Canduela P, et al. [Consensus document of the Spanish Society of Intensive and Critical Care Medicine and Coronary Units (SEMICYUC), the Spanish Society of Otorhinolaryngology and Head and Neck Surgery (SEORL-CCC) and the Spanish Society of Anesthesiology and Resuscitation (SEDAR) on tracheotomy in patients with COVID-19 infection]. Med Intensiva. 2020;44(8):493-9. DOI: 10.1016/j.medin.2020.05.002

30. Barrasa H, Rello J, Tejada S, Martin A, Balziskueta G, Vinuesa C, et al. SARS-CoV-2 in Spanish Intensive Care Units: Early experience with 15-day survival in Vitoria. Anaesth Crit Care Pain Med. 2020. DOI: 10.1016/j.accpm.2020.04.001 